\title{
Experimental Investigation on the Effects of Recycled Aggregate on Fracture Behavior of Polymer Concrete
}

\author{
João Marciano Laredo dos Reis*, Marco Antonio Godoy Jurumenha \\ Theoretical and Applied Mechanics Laboratory - LMTA, \\ Mechanical Engineering Post Graduate Program - PGMEC, \\ Universidade Federal Fluminense - UFF, \\ Rua Passo da Pátria 156, Bl. E, Sala 216, Niteroi, RJ, Brazil
}

Received: December 1, 2010; Revised July 8, 2011

\begin{abstract}
The sustainable management of solid wastes stimulates metallurgic and metal mechanics industries to look for safety applications for these wastes. The present paper examines the fracture behavior of polymer concrete (PC) manufactured with recycled foundry waste in substitution of fresh one. The recycled foundry sand is contaminated with polymer resin from the mold making process. Epoxy and unsaturated polyester resins were used as binder as cement substitute. The fracture results are analyzed by fracture energy; $\mathrm{G}_{\mathrm{f}}$, fracture toughness, $\mathrm{K}_{\mathrm{Ic}}$, and the crack tip opening displacement, CTOD. It is found that the use of recycled foundry sand significantly influences the fracture properties. The use of recycled sand increase fracture toughness and similar fracture energy is observed. These results show that recycled sand is an excellent alternative as raw material.
\end{abstract}

Keywords: fracture mechanics, polymer concrete, recycling, spent foundry, sand, PET resin

\section{Introduction}

Significant efforts have been made to understand the toughening components that contribute to the fracture toughness of brittle materials ${ }^{1-4}$. Polymer Concrete (PC) is a concrete-like composite, made of inorganic aggregates bonded together by a resin binder, in this case epoxy and unsaturated polyester resins, which substitutes the cement. The composition of PC is determined by its applications, and its strength is influenced by ratio of aggregate to resin content $t^{5,6}$. $\mathrm{PC}$ is used very efficiently in precast components. Indeed, polymer concrete has previously been mainly used for industrial flooring, retouching of damaged concrete structures and underground pipes. In comparison with conventional Port- land cement concrete, polymer concrete offers many advantages, such as higher strength, better chemical resistance and improved fracture toughness ${ }^{7}$.

Polymer concrete exhibits brittle failure behavior and therefore, it is important to improve its post-peak stress-strain behavior. Hence developing better PC systems and also characterizing the fracture and mechanical properties in terms of constituents are essential for the efficient utilization of PC.

Nowadays, because of the more exigent legislation regarding the environment and the market demand for environmentally friendly products, manufacturers are concerned to develop studies aimed at reducing the environmental impact, through lowering the amount of residues or treating those that are inevitably generated during production processes ${ }^{8}$. High costs associated with raw material extraction, as well as the damage that the extraction causes to the environment, are also important reasons to motivate the use of industrial process residues. Depletion of re-liable trustable raw material reserves and conservation of non-renewable sources also contribute to such reuse of waste materials.

The generation of residues is inherent to the casting process, mainly sand from molds and cores. Therefore, there is growing interest in the re-utilization of this sand, since the amount of residual sand is quite significant. Annually, around 2 million t of sand is disposed of, and the landfill costs are becoming very high at about US\$ 25.00 per t. In addition to the visual impact, another issue concerning foundry sand disposal is the possible contamination of underground water by metals and phenolic resins that could be lixiviated because of weathering.

Environmental acceptance of foundry sands in new products requires reliable knowledge of sand composition and sand residue composition variations, especially regarding their environmental characteristics. This information together with an effective quality control system is also necessary for the promotion of sand residue utilization. In general, these residues are classified as non-dangerous, class II, according to Brazilian laws. Therefore, recycled foundry sand presents high potential to be used as raw material. For this case, the foundry sand needs no pretreatment to be used as inert in PC. The recycling methodology consists in the application of mechanical treatments, "shake out" process (dry and wet friction), to separate the sand grains and obtain a fine size aggregate.

Another environmental issue originates from polyethylene terephthalate (PET) disposal. The production of such a large amount of PET bottles has created an environmental problem of gigantic proportions, since these bottles are not reused by the manufacturers and therefore are left as plastic waste, which do not decompose readily in nature ${ }^{9}$. The effective solution to solve this problem is to recycle these post consumer PET bottles into unsaturated polyester resin. Thermoset resins are quite expensive compared to Portland cement based materials. Recycling of PET bottles was done by glycolysis. The production of the unsaturated polyester resin based on recycled PET was done in two steps. The first step consisted of digesting the PET molecules by charging the PET scrap and a glycol into a reactor and heating for several hours in the presence of a transesterification catalyst. The second step consisted of adding dibasic acids to the solution to produce the polyester resin. The unsaturated polyester was then diluted with styrene to reduce its viscosity and allow its 
further cure to a solid (polymer) upon the addition of suitable free radical initiators and promoters. Curing took place because the styrene combined with the reactive double bonds of the polyester chains, thus linking them together and forming a strong three-dimensional polymer network ${ }^{10}$.

The proposal of this work is to use, as inert, recycled foundry sand with organic pollutants in substitution of fresh foundry sand in the manufacturing process of polymer concrete and characterizes the produced material. Besides using recycled foundry sand as substitute of natural aggregate, unsaturated polyester resin from recycled PET was also used as binder and compared to epoxy resin. The procedures involved in the production of the unsaturated polyester resin were not focused in this research.

A comparison between polymer concretes made with recycled raw materials and Portland cement concrete fracture properties were then evaluated. It is well known that concrete properties is influenced by several factor, one of them is the type off aggregate ${ }^{11}$. Also, the shape of aggregates has an influence on the concrete strength ${ }^{12}$.

\section{Material and Methods}

\subsection{Materials}

Four different polymer concrete formulations were prepared. Specimens were manufactured with $100 \%$ of fresh sand, for both binders, epoxy and unsaturated polyester recycled from PET and $100 \%$ of recycled foundry sand, also with both resins used. Resin content was $12 \%$ by weight, aggregate content was $88 \%$ and no filler was added in formulations. Previous studies carried ${ }^{13}$, considering an extensive experimental program, allowed an optimization of mortar formulations that are now being used in the present work. Optimization of mix design, regarding fracture toughness, was performed considering the influence of the following material parameters: resin type and aggregate grading.

The fresh aggregate was green foundry sand with a homogeneous grain size, employed in a 40/50 design, produced by JUNDU and used in the foundry industry. The foundry sand was previously dried before added to the polymeric resins in an automatic mixer. The recycled sand, like the fresh one, consists primarily of silica sand, coated with a thin film of burnt carbon, residual binder (bentonite, sea coal, resins/ chemicals) and dust. It contains cured alkaline-phenolic resin whereas cross-linking is activated with very strong organic acids. The initiator used to promote the free radical to produce polymer concrete due to its high performance, resulting in a high strength and polymerization on the system was a carboxylic acid called Triacetin (glycerol triacetate), which determines the speed of cross-linking. Because of the presence of phenols in foundry sand, there is some concern that precipitation percolating through stockpiles could mobilize leachable fractions, resulting in phenol discharges into surface or ground water supplies.

The epoxy resin system used here was RR515 from SILAEX, based on bisphenol A diglycidyl ether and an aliphatic amine hardener. This low viscosity (500-700 MPa) system was processed with a maximum mix-to-hardener ratio of 2:1. The polyester resin used, as binder was unsaturated polyester obtained from recycling PET. Unsaturated polyester resin is the most used resin to produce polymer concrete due to its high performance, resulting in a high strength and durability against aggressive environments, with low permeability and lower cost when compared to epoxy resins. Unsaturated polyester resin from PET showed similar results when used as binder to polymer concrete when compared to ordinary polyester resin, with the advantage of low manufacturing cost and processing energy and, of course contributing to reduce the plastic waste ${ }^{9,14}$. Resin properties are presented in Table 1 .
Table 1. Properties of epoxy and polyester resins.

\begin{tabular}{lcc}
\hline \multicolumn{1}{c}{ Property } & Epoxy & Polyester \\
\hline Viscosity at $250 \mathrm{C} \mu(\mathrm{cP})$ & $12000-13000$ & $250-350$ \\
Density $\rho\left(\mathrm{g} \cdot \mathrm{cm}^{-3}\right)$ & 1.16 & 1.09 \\
Heat distortion temperature HDT $\left({ }^{\circ} \mathrm{C}\right)$ & 100 & 85 \\
Modulus of elasticity E $(\mathrm{GPa})$ & 5.0 & 3.3 \\
Flexural strength $(\mathrm{MPa})$ & 60 & 45 \\
Tensile strength $(\mathrm{MPa})$ & 73 & 40 \\
Maximum elongation $(\%)$ & 4 & 1 \\
\hline
\end{tabular}

Polymer concrete fracture specimens were compacted in a steel mold of dimensions of $30 \times 60 \times 250 \mathrm{~mm}^{3[1]}$. The specimens were initially cured at room temperature. The samples were notched using a $2 \mathrm{~mm}$ diamond saw to a $20 \mathrm{~mm}$ depth.

The PC formulations were manufactured following the specifications of RILEM TC113/PC-2 ${ }^{[15]}$. Specimens were then postcured during 3 hours at $80{ }^{\circ} \mathrm{C}$.

\subsection{Methods}

To determine the fracture properties, three-point bending tests were conducted using a universal testing machine with a crosshead speed of $0.5 \mathrm{~mm} / \mathrm{min}$. The crack mouth opening displacement (CMOD) was measured using a COD gauge clipped to the bottom of the beam and held in position by two $1.5 \mathrm{~mm}$ steel knife edges glued to the specimen, as shown in Figure 1.

Fracture energy, $\mathrm{G}_{\mathrm{f}}$, fracture toughness, $\mathrm{K}_{\mathrm{Ic}}$ are the main parameters determined, CTOD and E, according to Jenq and Shah ${ }^{1}$ and RILEM Technical Committee ${ }^{16}$ are also determined.

According to the RILEM Technical Committee ${ }^{17}$, the fracture energy, $G_{f}$, in single edge notched beams when three point bending tests are performed to specimens can be calculated as

$$
G_{f}=\frac{W_{0}-m g \delta_{0}}{A_{l i g}}
$$

where $\mathrm{W}_{0}$ is the area under the load vs. deflection curve $\left(\mathrm{N} \cdot \mathrm{m}^{-1}\right)$, $\mathrm{m} . \mathrm{g}$ is the self-weight of the specimen between supports $(\mathrm{kg}), \delta_{0}$ is the maximum displacement $(\mathrm{m})$, and $\mathrm{A}_{\operatorname{lig}}$ is the fracture area $[\mathrm{d}(\mathrm{b}-\mathrm{a})]$ $\left(\mathrm{m}^{2}\right)$; $\mathrm{b}$ and $\mathrm{d}$ are the height and width of the beam, respectively. The results correspond to the mean values of at least three tests.

The Fracture Energy, $\mathrm{G}_{\mathrm{f}}$, which also termed, as the "work of fracture" was first proposed by Hillerborg ${ }^{18}$ and his co-workers as an indirect surface energy measure of cemetitious materials. In the present work, the method to determine $\mathrm{G}_{\mathrm{f}}$ will be referred to as the Fracture Energy method.

The independency of $\mathrm{G}_{\mathrm{f}}$ related to the size of the specimen seams to be assured only in flexural inverted tests, i.e. where the load comes from the bottom to the top ${ }^{18}$. The experimental analysis done by Hillerborg and the numerical analysis done by other researchers describe that the absorbed energy increase with the increase of the test specimen. After several tests they also reconfirmed that the fracture energy $G_{f}$ depends on the specimens size and principally from the notch/depth relation. They verified that lower the notch/depth ratio higher the $\mathrm{G}_{\mathrm{f}}$ and increasing the dimension of the samples the absorbed energy out of the fracture zone increase. This incensement is higher as lower is the resistance of the material in compression. Increasing the aggregate size in a way that will not compromise the workability of the mix preparation and the material strength the fracture energy increase, in the same way the superficial material 
rugosity increase. Increasing the strength of the inerts, matrix and matrix-inert interface, the material strength increase resulting in higher fracture energy values ${ }^{12}$.

To identify fracture toughness of PC, the Two Parameter Method $(\mathrm{TPM})^{1}$ was used. This method is a direct method to calculate two size independent fracture parameters, i.e., critical stress intensity factor, $\mathrm{K}_{\mathrm{Ic}}$ and critical crack tip opening displacement $\mathrm{CTOD}_{\mathrm{c}}$ which is the displacement of the surfaces of a crack normal to the original crack plane at the tip of the fatigue pre-crack.

$\mathrm{K}_{\mathrm{Ic}}$ is a measurement of a material's resistance to crack extension when the stress state near the crack tip is predominantly plane strain, plastic deformation is limited, and opening mode monotonic load is applied and can be expressed as, in (MPa $\sqrt{\mathrm{m}}$ )

$$
K_{I c}=\frac{3 P_{\max } S}{2 W^{2} B} \sqrt{\pi \underline{a}} F(\alpha)
$$

in which a is the effective critical crack length

$$
F(\alpha)=\frac{1}{\sqrt{\pi}} \frac{1.99-\alpha(1-\alpha)\left(2.15-3.95 \alpha+2.7 \alpha^{2}\right)}{(1+2 \alpha)(1-\alpha)^{3 / 2}}
$$

where $\alpha$ is a/W, $\mathrm{P}_{\max }$ is the measured maximum load $[\mathrm{N}], \mathrm{S}, \mathrm{W}$ and $\mathrm{B}$ are the span, depth and width, respectively. The results correspond to the mean values of at least three tests.

The value of CTOD is calculated using Equation 4, as

$$
\operatorname{CTOD}_{c}=\frac{6 P_{\max } S \underline{a}}{W^{2} B E} V_{1}(\alpha)\left\{\left(1-\beta^{2}\right)+(-1.149 \alpha+1.081)\left(\beta-\beta^{2}\right)\right\}^{1 / 2}
$$

where $\beta$ is $a_{0} / a$.

The Young Modulus (E) is calculated from the measured initial compliance $\mathrm{C}_{\mathrm{i}}$ using equation
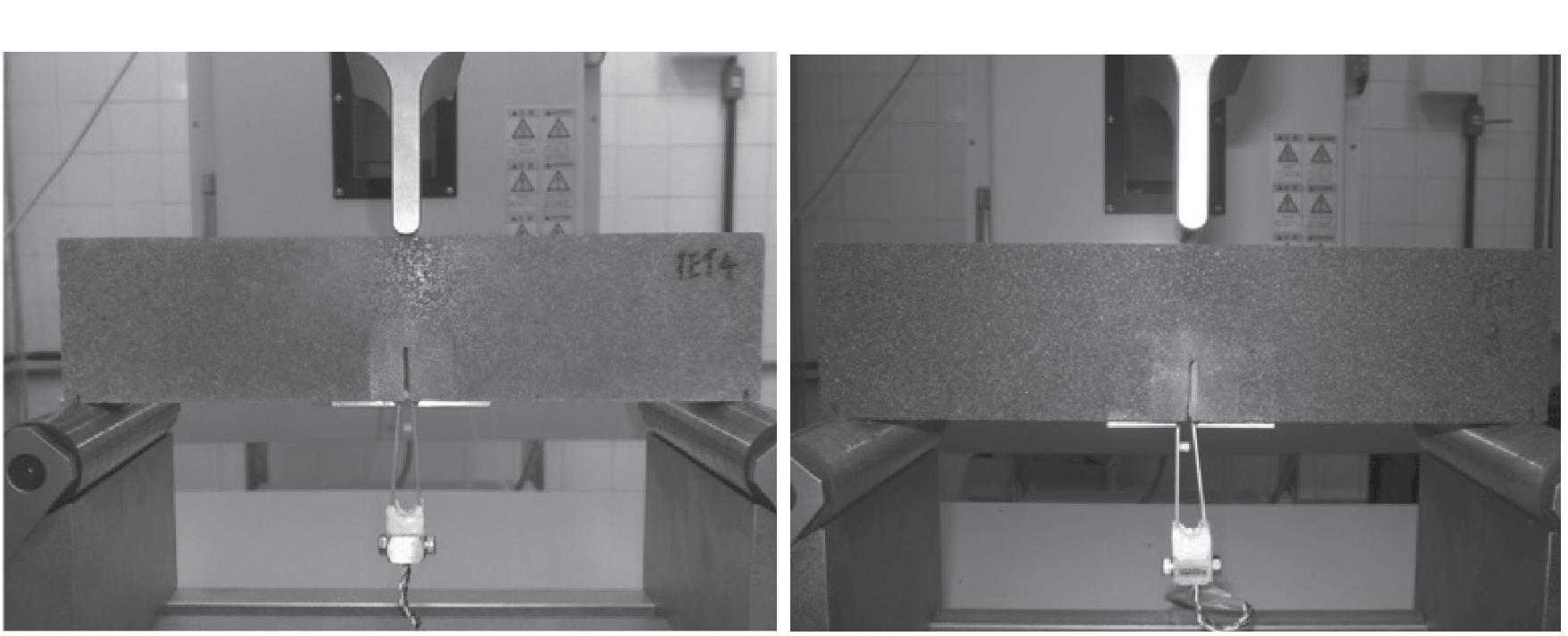

$$
E=\frac{6 S a_{0} V_{1}(\alpha)}{\left(C_{i} W^{2} B\right)}
$$

in which $\mathrm{S}$ is the specimen loading span, $\mathrm{a}_{0}$ is the initial notch depth, $\mathrm{H}_{0}$ is the thickness of clip gauge holder, $\mathrm{W}$ and $\mathrm{B}$ are the beam depth and width respectively.

$$
V_{1}(\alpha)=0.76-2.28 \alpha+3.78 \alpha^{2}-2.04 \alpha^{3}+\frac{0.66}{(1-\alpha)^{2}}
$$

and

$$
\alpha=\frac{\left(a_{0}+H_{0}\right)}{\left(W+H_{0}\right)}
$$

Based on finite element analysis, the contribution of the clip gauge holder thickness $\left(\mathrm{H}_{0}\right)$ is included in the function $\mathrm{V}_{1}{ }^{[1]}$.

\section{Results and Discussion}

Table 2 summarizes the fracture results of all polymer concrete formulations tested, where the first letter represents the aggregate type, $\mathrm{F}$ for fresh sand and $\mathrm{R}$ for recycled foundry sand and the second letter represents the polymer binder, E for epoxy and $\mathrm{P}$ for unsaturated polyester from recycled PET.

From Table 2 it can be seen a reduce of $15.2 \%$ when epoxy polymer concrete manufactured with fresh sand, FE, is compared to recycled foundry sand ones, RE. Calculating the results of unsaturated polyester resin from recycled PET polymer concrete a $3.4 \%$ decrease was measured in the fracture energy when fresh sand specimens were compared to recycled foundry sand.

Despite what was expected from previous studies ${ }^{19}$, the fracture toughness of polymer concrete manufactured with recycled foundry

Figure 1. Fracture test set-up.

Table 2. Fracture Properties of PC (Average | St.Dev.).

\begin{tabular}{llccc}
\hline \multicolumn{1}{c}{ Formulation } & \multicolumn{1}{c}{$\mathrm{G}_{\mathrm{f}}\left(\mathrm{N} \cdot \mathrm{m}^{-1}\right)$} & $\mathrm{K}_{\mathrm{Ic}}(\mathrm{MPa} \sqrt{\mathrm{m}})$ & $\mathrm{CTOD}_{\mathrm{c}}(\mathrm{mm})$ & $\mathrm{E}(\mathrm{GPa})$ \\
\hline Fresh epoxy (FE) & $357.36 \pm 30.41$ & $1.58 \pm 0.07$ & 0.012 & $11.94 \pm 1.26$ \\
Recycled epoxy (RE) & $303.14 \pm 22.34$ & $2.20 \pm 0.03$ & 0.004 & $13.53 \pm 2.58$ \\
Fresh PET (FP) & $200.24 \pm 8.91$ & $1.12 \pm 0.19$ & 0.022 & $15.43 \pm 1.86$ \\
Recycled PET (RP) & $193.48 \pm 20.66$ & $2.48 \pm 0.09$ & 0.006 & $10.96 \pm 0.77$ \\
\hline
\end{tabular}




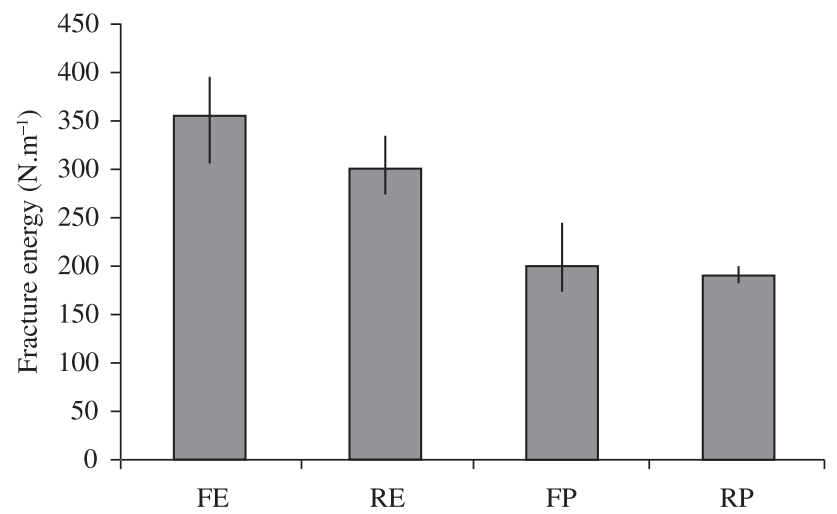

Figure 2. Fracture energy test results comparison.

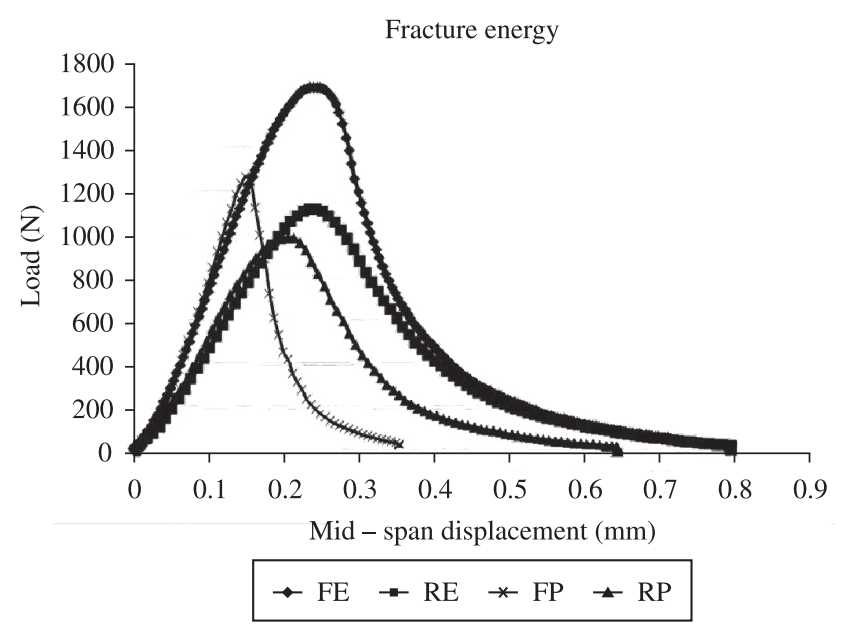

Figure 3. Typical load vs. mid-span displacement test results.

sand was substantially high for both binders, epoxy and unsaturated polyester from recycled PET when compared to fresh sand specimens. In fact, the increment of polymer concrete resistance to crack initiation for epoxy binder was $39.2 \%$ higher comparing fresh to recycled aggregate. Comparing unsaturated polyester from recycled PET as binder an increase of $121.4 \%$ was observed on the fracture toughness. The modulus of elasticity, (E), follows the fracture parameters of epoxy binder polymer concrete formulations. A $13.3 \%$ improve was computed but a decrease of $28.9 \%$ was observed when unsaturated polyester resin PC was compared, fresh sand to recycled one.

Figure 2 presents the fracture energy comparison between all tested formulations.

It can be seen from Figure 2 that a small decrease I fracture energy occurs when recycled foundry sand is used as fresh sand substitute in epoxy polymer concrete specimens. When unsaturated polyester from recycled PET polymer concrete is analyzed no significant variation is observed.

The typical fracture energy curves obtained from all specimens tested are presented in Figure 3.

Figure 3 shows that the fresh sand epoxy polymer concrete, (FE), demands more energy to create one unit area of a crack and fresh sand unsaturated polyester polymer concrete, (FP) need less energy for crack growth. Recycled foundry sans with epoxy binder has similar fracture energy, $G_{f}$, results to fresh sand. Fresh sand unsaturated polyester PC behaves totally different from the others formulations. A brittle behavior was observed during tests making

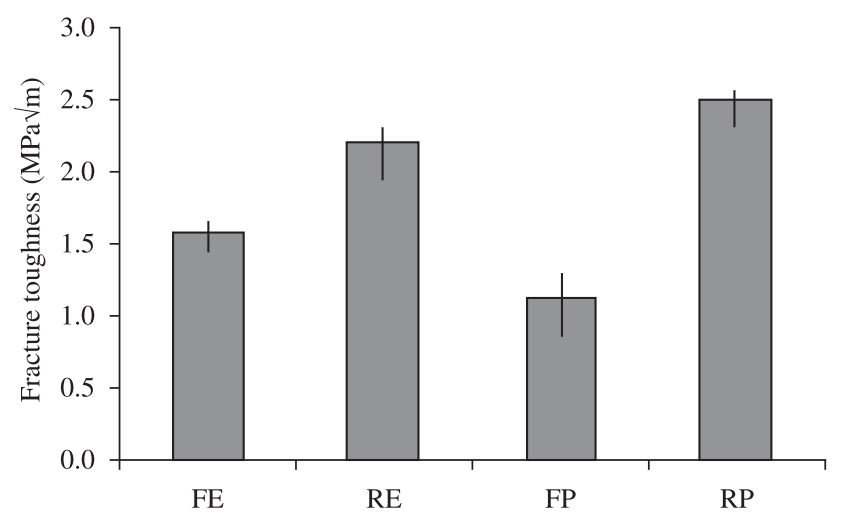

Figure 4. Fracture toughness test result comparison.

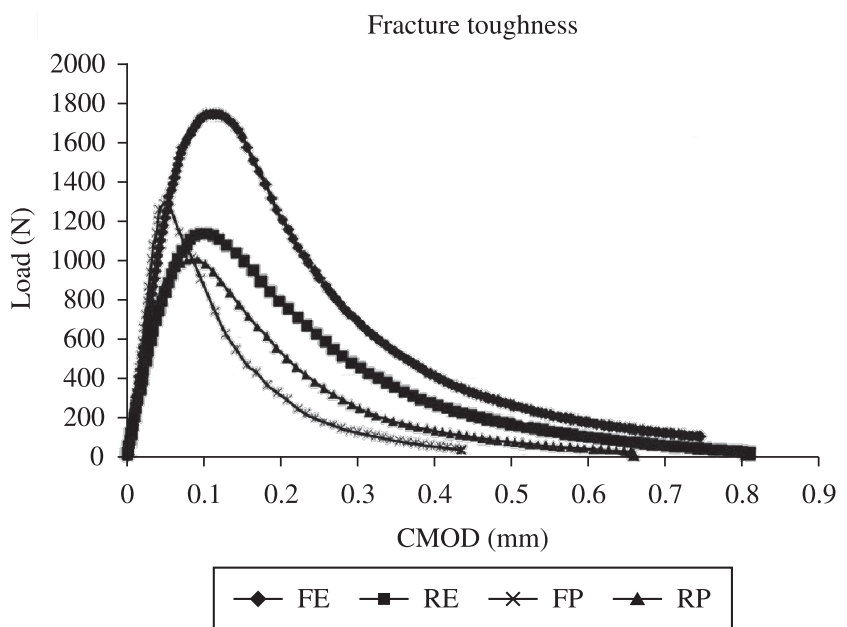

Figure 5. Typical load vs. CMOD test results.

FP less resistant to crack propagation. From all results presented a softer crack propagation was reported.

A fracture toughness comparison between all tested specimens is presented in Figure 4

According to Figure 4 a significant increase in the fracture toughness of both epoxy and unsaturated polyester polymer concrete manufactured with recycled foundry sand is observed when compared to fresh sand polymer concrete. For the unsaturated polyester polymer concrete the increase is more than $100 \%$.

The typical Load-CMOD curves obtained from epoxy and unsaturated polyester from recycled PET polymer concrete manufactured with recycled and fresh foundry sand is shown in Figure 5.

All Load-CMOD curves of polymer concrete with different aggregates and binders show similar pattern. It can be seen that the slopes of the initial part of the curves are almost the same, which means that all formulations has similar stiffness. The post-peak load section of the curves displays a diminish of the load with a smooth pattern, except for FP which present a more brittle behavior.

\section{Conclusions}

In this research work a fracture properties comparison between fresh and recycled foundry sand polymer concrete manufactured with epoxy an unsaturated polyester resin from recycled PET were performed. Polymer concrete is strongly dependent on the type of matrix used. Epoxy matrix polymer concrete has higher fracture 
characteristics than unsaturated polyester ones. Epoxy polymer concrete made with recycled foundry sand has higher fracture toughness, $\mathrm{K}_{\mathrm{Ic}}$ and slight lower fracture energy, $\mathrm{G}_{\mathrm{f}}$, when compared to fresh sand polymer concrete. The use of recycled foundry sand improves significantly the resistance to crack opening of unsaturated polyester PC. The fracture energy remains the same. Also, the substitution of fresh sand by recycled foundry sand produces a less brittle and stiffer polymer concrete. Recycled foundry sand could be very conveniently used in making good quality polymer concrete and construction materials.

\section{Acknowledgements}

The authors thank the Research Foundation of the State of Rio de Janeiro (FAPERJ) and The Brazilian National Council for Scientific and Technological Development $(\mathrm{CNPq})$ for supporting part of the work presented here.

\section{References}

1. Jenq YS and Shah SP. Two parameter fracture model for concrete. Journal of Engineering Mechanics. 1985; 111:1227-1241. http://dx.doi. org/10.1061/(ASCE)0733-9399(1985)111:10(1227)

2. Bazant ZP. Concrete fracture models: testing and practice. Engineering Fracture Mechanics. 2002; 69:165-205. http://dx.doi.org/10.1016/S00137944(01)00084-4

3. Rossello C and Elices M. Fracture of model concrete 1. types of fracture and crack path. Cement \& Concrete Researh. 2004; 34:1441-1450. http://dx.doi.org/10.1016/j.cemconres.2004.01.028

4. Rossello C, Elices M and Guinea GV. Fracture of model concrete: 2. fracture energy and characteristic length. Cement \& Concrete Research. 2006; 36:1345-1353. http://dx.doi.org/10.1016/j.cemconres.2005.04.016

5. Ribeiro M, Tavares C, Ferreira AJM and Fernandes AA. Bending characteristics of resin concretes. Materials Research. 2003; 6:247-254. http://dx.doi.org/10.1590/S1516-14392003000200021

6. Reis JML. Effect of textile waste on the mechanical properties of polymer concrete. Materials Research. 2009; 12:63-67. http://dx.doi.org/10.1590/ S1516-14392009000100007

7. Ohama Y. Recent progress in concrete-polymer composites. Advanced Cement Based Materials. 1997; 5:31-40. http://dx.doi.org/10.1016/ S1065-7355(96)00005-3
8. Bragança SR, Vicenzi J, Guerino K and Bergmann CP. Recycling of iron foundry sand and glass waste as raw material for production of whiteware. Waste Management Research. 2006; 24:60-66. http://dx.doi. org/10.1177/0734242X06061155

9. Mahdi F, Khan AA and Abbas H. Physiochemical properties of polymer mortar composites using resins derived from post-consumer pet bottles. Cement \& Concrete Composites. 2007; 29:241-48. http://dx.doi. org/10.1016/j.cemconcomp.2006.11.009

10. Rebeiz KS. Time-temperature properties of polymer concrete using recycled pet. Cement \& Concrete Composites. 1995; 17:119-24. http://dx.doi.org/10.1016/0958-9465(94)00004-I

11. Rocco $\mathrm{C}$ and Elices M. Effect of aggregate shape on the mechanical properties of a simple concrete. Engineering Fracture Mechanics. 2009; 76:286-98. http://dx.doi.org/10.1016/j.engfracmech.2008.10.010

12. Elices $M$ and Rocco $C$. Effect of aggregate size on the fracture and mechanical properties of a simple concrete. Engineering Fracture Mechanics. 2008; 75:3839-3851. http://dx.doi.org/10.1016/j. engfracmech.2008.02.011

13. Silva LPN and Reis JML. Mechanical properties of textile waste reinforced polymer concrete. In: Proceedings of the 19th international congress of mechanical engineering; 2007; Brasília. Rio de Janeiro: Editora. ABCM; 2007.

14. Karayannidis GP, Achilias DS, Sideridou I and Bikiaris D. Alkyd resins derived from glycolized waste poly(ethylene terephthalate). European Polymer Journal. 2005; 41:201-210. http://dx.doi.org/10.1016/j. eurpolymj.2004.10.001

15. Technical Committee RILEM PC-2. Method of making polymer concrete and mortar specimens. International Union of Testing and Research Laboratories for Materials and Structures.

16. Technical Committee RILEM TC89-FMT. Fracture mechanics of concrete test methods. Materials and Structures. 1991; 23:457-460.

17. Technical Committee RILEM 50-FMC. Détermination de l'énergie de rupture des mortiers et bétons par flexion «trois points» de poutres encochées. Materials and Structures. 1985; 18:285-90. http://dx.doi. org/10.1007/BF02472917

18. Hillerborg A. Concrete fracture energy tests performed by 9 different laboratories according to a draft RILEM recommendation. Lund, Sweden; 1983. Report to RILEM TC50- FMC, Report TVMB-3015.

19. Sousa LM, Reis JML and Ferreira AJM. Characterization of Polymer Concrete made with Recycled Aggregate. In: Proceedings of the 11th European conference on Composite Materials; 2004; Rhodes. Rhodes: ESCM; 2004. 